\title{
Labor Mobility, Goods Tradability, and Efficient Allocation of Disaster Risk
}

AUTHOR(S):

Na, Jong-il; Okada, Norio; Fang, Liping

\section{CITATION:}

Na, Jong-il ... [et al]. Labor Mobility, Goods Tradability, and Efficient Allocation of Disaster Risk. Proceedings of the 2009 IEEE International Conference on Systems, Man, and Cybernetics 2009: 1923-1928

\section{ISSUE DATE:}

2009-10

URL:

http://hdl.handle.net/2433/109799

\section{RIGHT:}

(c) 2009 IEEE. Personal use of this material is permitted. However, permission to reprint/republish this material for advertising or promotional purposes or for creating new collective works for resale or redistribution to servers or lists, or to reuse any copyrighted component of this work in other works must be obtained from the IEEE. 


\section{Labor Mobility, Goods Tradability, and Efficient Allocation of Disaster Risk}

\author{
Tao Ye \\ Graduate School of Engineering \\ Kyoto University \\ Kyoto, Japan \\ yetao@drs.dpri.kyoto-u.ac.jp
}

\author{
Muneta Yokomatsu and Norio Okada \\ Disaster Prevention Research Institute \\ Kyoto University \\ Kyoto, Japan \\ yoko@drs.dpri.kyoto-u.ac.jp \\ n okada@drs.dpri.kyoto-u.ac.jp
}

\begin{abstract}
Given the role of agriculture sector in an economy and its vulnerability in terms of disasters, direct monetary transfers are paid from tax-payers to agriculture producers in many countries. Government policies are expected not only to provide higher and more stable income to producers but also to create incentives to attract rural households to continue farming. Nevertheless, these policies have been doubted for inducing economic inefficiency because the later piece of effect masks the market signal for resources and risk allocation. This research uses a dual-economy model with inter-sectoral flow of labor and commodity to justify government policies that discourages rural producers to work in urban sectors. The result of the model shows that when there is no disaster insurance market, migration behavior should be controlled and fiscal transfer do improve economic efficiency. When there is disaster insurance market in this economy, market mechanism can achieve social optimal allocation if goods tradability is perfect. When goods tradability is imperfect, migration behavior in the insurance equilibrium should be controlled if the migration costs is low, or vice versa. Government intervention is necessary to encourage or discourage migration in each case, respectively.
\end{abstract}

Keywords-inter-sectoral disaster risk diversification, labor mobility, goods tradability, government intervention

\section{INTRODUCTION}

Agriculture is such an important sector to an economy that its role has been intensively and repeatedly discussed by economists $[1,2,3]$. It is also the common wisdom that "agriculture is subject to greater risk and uncertainty than most other sectors of the economy" [4]. In many countries it is taken special care of by governments. Various kinds of policies are carried out to support rural producers, e.g. direct product price intervention, lump-sum subsidy for farming, lump-sum subsidy for technique advance, disaster aid, as well as crop insurance programs with heavy premium subsidy. Among these policy instruments, government initiatives which are not neural to producers' decision-making have been doubted for undermining economic efficiency, as they are likely to hamper resources from flowing to the places where they can be more efficiently used [5]. For instance, the rural-urban disparity in China has induced decade-long seasonal migration pattern in Mainland China. The household registration system (Hukou), however, has been inducing huge transaction costs for rural laborers to work in urban sectors and the removal of it may induce large flow of permanent rural-to-urban migration [6].
Recently, the Chinese government has carried out a series of policy instruments as mentioned to slow down the widening rural-urban income gap [7]. Nevertheless, the removing of household registration system which can definitely increase the labor market efficiency is not among the policies carried out.

One of the major reasons of "inefficient" allocation is the worry that free migration may undermine the self-sufficiency of food of a country. It is a trade-off among economic efficiency, equality, and risk-bearing. This research is then to discuss whether the migration of farmers to the sectors paying higher and more stable salary should be encouraged or discouraged. The model uses the framework of inter-sectoral disaster risk diversification in a simple dual-economy structure, following the most classic manner of discussion on interregional and inter-sectoral resources and risk allocation in the field of public economics [8,9]. Labor mobility and goods tradability are taken into account as the susceptible excuses for "inefficient" policy. In the model, the assumptions on factor mobility and goods tradability are abstracted from what is going on in China. Meanwhile, the concept of collective risk $[10,11]$ is incorporated into this model so that the feature of disaster risk, mutual dependency among risk units, is reflected.

The structure of this paper is arranged as follows: Section II introduces key assumptions of this model. In section III, IV, and $\mathrm{V}$, the model introduces its benchmark equilibrium, social optimum and Malinvaud-Arrow insurance $[12,13]$ equilibrium, respectively. They are then compared in section VI to verify the policy instrument. Until here the model is described with the fewest details due to the page limit. For details of model development, please kindly refer to [14]. Based on the basic results, further discussion is put forward on optional intervention approaches to improve the efficiency of decentralized approaches. In the final section, the model is concluded and some discussion is put on policy implications as well as further research topics.

\section{THE MODEL}

\section{A. Key assumptions}

\section{1) The small world in the model}

Consider a small closed economy with two regions and two sectors, both rural and urban. The rural sector is in the rural area, producing the so-called rural goods while the urban sector is in the urban area and produces urban goods. Products are 
used for private consumption by residents and physical capital investment. Suppose there are $N_{1}$ people residing in the rural area and $N_{2}$ residing in the urban area. Labors are assumed to be homogeneous in terms of natural endowment, including the quality of human capital for all residents and agriculture land for rural residents. An individual's welfare state is determined by his consumption on both kinds of goods.

\section{2) Factor mobility}

The rural-urban migration in China is a kind of ex ante, seasonal, and circular rural-to-urban move. Due to the existence of household registration (Hukou) system, it is very difficult to change one's status from "rural resident" to "urban resident". Therefore, most migrants leave families behind, return to their families during periods of holiday or unemployment, and seldom assimilate with the urban population $[15,16]$. They generally start to move to urban areas right after the Chinese New Year, which is ahead of the planting season. They work in large cities for the whole year and return to hometown when the festival comes again. In this sense, the model is described in a static manner as the "migration" is actually seasonal move which repeats from one year to another. The move is also unidirectional: currently there is no evidence showing that urban residents are moving to work in rural sectors in China.

Labor mobility is represented by a lump-sum transaction cost in this model, denoting the costs for travelling, getting job permission, and hunting for a job. It is assumed that all seasonal workers can get jobs in the urban sector. Unemployment is popular in inter-regional migration models but is not taken into account in this model.

In rural China, land for agriculture production is owned by the "collective" while the "use-right" is allocated to farming households, which was prohibited to transfer. When a household leaves for urban areas for a seasonal job, it retains its use-right but asks someone else, e.g. friends, relatives, or neighbors, to cultivate the land for it. In this model it is assumed that the land is left uncultivated if the "user" goes to the urban sector, for the sake of simplicity. In this sense, factor mobility in this model refers only to labor mobility.

\section{B. Events and time sequence}

1) Decision-making on the seasonal move

At the beginning of each period, rural residents consider whether to move to the urban area or not. If one decides to stay, he cultivates the land and is then called the "rural worker". If one decides to move, he is then called the "seasonal worker". So before the seasonal move starts we have two groups of individuals: rural residents and urban residents. After that, we have three groups of individuals, rural workers, urban residents and seasonal workers, which are given subscripts of 1,2 and 3 in the following part of this paper, respectively.

\section{2) Production}

In this phase, workers start to produce goods. Rural workers produce the so-called "rural goods" on household basis. It is assumed that each rural worker contributes inelastically a unit of labor in production, which is assumed to be an optimum amount. This assumption stands in this model as our focus is rural-urban migration rather than on-farm decision-making. If no uncertainty is taken into consideration, rural workers will exactly produce the same amount of output, $X$.

In the urban sector, production is finished in an aggregate manner following technology of $Y=(K, L)$, in which $K$ is the total social capital stock for production and $L$ is the total labor force engaged. The wage rate is determined by the marginal productivity with respect to labor, $w=Y_{L}(K, L)$. It is assumed that the technology shows constant-return-to-scale with respect to labor input so that $w$ is a constant. This assumption excludes the possibility of externality induced by technology and helps to catch the essential impact from mobility and tradability. An urban worker's working hours is mandatorily designated, e.g. 8 hours/ day. It can be further simplified by normalizing working hours to 1 . Thus the labor income for an urban worker is exactly $w$

The move to the urban area is costly. Rural residents who move to work in urban sector are supposed to pay a lump-sum cost, denoted by $c$, for the move. For the sake of simplicity, the model allows seasonal workers to pay this cost after wages are paid. So the actual income for a seasonal worker is $w-c$.

\section{3) The state of the world}

In this model production of both sectors is exposed to natural disaster risk. Natural disaster risk is defined as a twostage compound lottery according to the collective risk theorem $[10,11]$ : firstly, the nature chooses the size, geographical location, and severity of the hazard, determining the collective state of the world $t=\{0,1, \ldots, T-1\}$. As for rural sector, in accordance to assumption on production functions, it is assumed that rural production activity could fall in different individual states when a certain collective state occurs and consequently rural workers may have different harvesting after some disaster events $X(s), s=\{0,1, \ldots, S-1\}$. On the other hand, the entire urban sector falls into some same state as it is assumed to be a "big" company and all urban workers will have uniform ex post income $w(t)$. In other words, individual states of urban workers coincide with the collective states of the world.

The probability for a piece of land being in a joint state $(s, t)$ is $\pi(s, t)>0$, with $\sum_{s, t} \pi(s, t)=1$. The probability of the production of a specific plot of land with output of $X(s)$ could be derived as the conditional probability of $\pi(s \mid t)=\pi(s, t) / \sum_{s^{\prime}} \pi\left(s^{\prime}, t\right)$. Then exactly there would be $\pi(s \mid t) \cdot N_{1}$ pieces of land in individual state $s$ when collective state $t$ occurs. When seasonal moves are taken into account, the number of cultivated land reduces by $n$, the same as the number of seasonal workers. The theorem applies when we assume that the land of seasonal workers is distributed uniformly in the space. In this sense, the number of cultivated but damaged land in a joint state of $(s, t)$ is $\pi(s \mid t) \cdot N_{1} \cdot\left(N_{1}-n\right) / N_{1}=$ $\pi(s \mid t) \cdot\left(N_{1}-n\right)$, while social aggregate output of rural goods is $\sum_{s} \pi(s \mid t)\left(N_{1}-n\right) X(s)=\left(N_{1}-n\right) \operatorname{EX}(t)$.

\section{4) Trade and consumption}

Consumption of workers starts after the state of the world is known. Goods tradability is denoted by transaction costs for 
delivering per unit of rural and urban goods, $\delta_{\mathrm{x}}$ and $\delta_{\mathrm{y}}$, respectively. If the relative price of rural goods to urban goods is denoted by $p$, the budget constraints for workers are

$$
\begin{gathered}
p(t)\left[X(s)-x_{1}(s, t)\right]=\left(1+\delta_{y}\right) y_{1}(s, t), \text { for all } s, t, \\
{\left[p(t)+\delta_{x}\right] x_{2}(t)+y_{2}(t)=w(t), \text { for all } t, \text { and }} \\
{\left[p(t)+\delta_{x}\right] x_{3}(t)+y_{3}(t)=w(t)-c, \text { for all } t}
\end{gathered}
$$

Seasonal workers are supposed to pay $\delta_{y}$ instead of $\delta_{x}$. It is because seasonal workers stay in the urban area almost all the time in a year except a few days for holiday at hometown. Social budget constraints are denoted as:

$$
\begin{gathered}
\sum_{N_{1}-n}\left[X-x_{1}(s, t)\right]-N_{2} x_{2}(t)-n x_{3}(t) \leq 0, \text { for all } s, t \\
\sum_{N_{1}-n} y_{1}(s, t)+N_{2} y_{2}(t)+n y_{3}(t) \leq Y\left(N_{2}+n\right)-C \text {, for all } s, t,
\end{gathered}
$$

in which $C$ is the social aggregate consumption on transportation to move seasonal workers and goods between rural and urban areas. Since the model is in a static manner, dynamic investment decision is not essential to our discussion. Therefore, discussion on the capital stock investment for production of the next period can be skipped. By assuming the economy is running at its steady state where the return to capital stock is fixed, social consumable urban goods can actually be denoted by $Y\left(N_{2}+n\right)-C=\left(N_{2}+n\right) w(t)-C$.

\section{THE BENCHMARK CASE}

\section{A. Individuals' optimum choice}

After the state of the world is determined, an individual tries to maximize his ex post utility given his state-contingent wealth, $\omega_{i}(\cdot)$. In this benchmark case, it is equivalent to statecontingent labor income, $e_{i}(\cdot)$. We assume that the ex post utility function shows the preference of constant-elasticity-ofsubstitution (CES) between rural and urban goods with elasticity of $\epsilon$ and $u_{x}>0>u_{x x}, u_{y}>0>u_{y y}, u_{x y}>0$. According to the budget constraint of individuals and the balance in goods markets, ex post equilibrium follows

$$
p(t)+\delta_{x}=\epsilon B(t) /\left[\left(N_{1}-n\right) \operatorname{EX}(t)\right], \text { for all } t,
$$

with $B(t)=N_{2} w(t)+n[w(t)-c]$. In this sense, individuals' optimum choices are derived as:

$$
\begin{gathered}
x_{1}^{*}(s, t)=\beta X(s), y_{1}^{*}(s, t)=(1-\beta) p(t) X(s) /\left(1+\delta_{y}\right) \\
x_{2}^{*}(t)=\beta w(t) /\left(p(t)+\delta_{x}\right), y_{2}^{*}(t)=(1-\beta) w(t), \\
x_{3}^{*}(t)=\beta[w(t)-c] /\left(p(t)+\delta_{x}\right), y_{3}^{*}(t)=(1-\beta)[w(t)-c]
\end{gathered}
$$

for all $s, t$ with $\beta=\epsilon /(1+\epsilon)$. Social aggregate economic value of goods can be denoted as

$$
\Omega(t)=(1+\epsilon) B(t)-\delta_{x}\left(N_{1}-n\right) \operatorname{EX}(t), \text { for all } t
$$

An individual's ex post indirect utility depends only on his state-contingent wealth and the relative price:

$$
v_{i}(\cdot)=A_{i}(p(t)) \omega_{i}(\cdot), \text { for all } t,
$$

with $A_{1}(p(t))=(\epsilon+1)^{-1}\left(1+\delta_{y}\right)^{-\frac{1}{\epsilon+1}}[\epsilon / p(t)]^{\frac{\epsilon}{\epsilon+1}}$ and

$A_{i}(p(t))=(\epsilon+1)^{-1} \epsilon^{\frac{\epsilon}{\epsilon+1}}\left[p(t)+\delta_{x}\right]^{-\frac{\epsilon}{\epsilon+1}}$ for $i=2,3$ and for all $t$.

We further assume that individuals' ex ante utility is a function $W\left(v_{i}(\cdot)\right)$ showing constant relative risk aversion (CRRA) preference. Expected ex ante utility can be derived as $\mathrm{E} W_{i}=\sum_{s, t} \pi(\cdot) W_{i}\left(v_{i}(\cdot)\right)$. The ex ante equilibrium is reached when the marginal seasonal worker finds himself indifferent of working either in the rural sector or the urban sector, that $\mathrm{E} W_{3}=\mathrm{E} W_{1}$. As comparative statics imply that expected ex ante utility show monotonic change with respect to the change in the number of seasonal workers, ex ante equilibrium exists and is unique.

\section{SOCIAL OPTIMUM ALLOCATION OF DISASTER RISK}

Consider the optimal risk allocation and population distribution problem in the society. The central planner is supposed to maximize the weighted sum of expected utility functions. The social optimization problem is:

$$
\max _{n, \omega_{1}(s, t), \omega_{2}(t), \omega_{3}(t)} U=\gamma_{1} \sum_{N_{1}-n} \mathrm{E} W_{1}+\gamma_{2} N_{2} \mathrm{E} W_{2}+\gamma_{3} n \mathrm{E} W_{3},
$$

in which $\gamma_{i}$ denotes the weight allocated to individuals of type $i$ by the central planner. This problem is subjected to

$$
\begin{gathered}
\alpha(t): \sum \omega_{1}(s, t)+N_{2} \omega_{2}(t)+n \omega_{3}(t)=\Omega(t), \\
\mu: \mathrm{E} W_{1}=\mathrm{E} W_{3} \\
0 \leq n \leq N_{1}, \omega_{1}(s, t), \omega_{2}(t), \omega_{3}(t) \geq 0, \text { for all } s, t
\end{gathered}
$$

The Greek letter ahead of each constraint is its corresponding Lagrange Multiplier. By assuming interior solutions, first-order conditions are

$$
\begin{aligned}
& \frac{\alpha(t)}{\pi(t)}=\frac{\gamma_{1}\left(N_{1}-n\right)+\mu}{N_{1}-n} \cdot \frac{d W_{1}(\cdot)}{d \omega_{1}(s, t)}=\gamma_{2} \frac{d W_{2}(\cdot)}{d \omega_{2}(t)}=\frac{\gamma_{3} n-\mu}{n} \cdot \frac{d W_{3}(\cdot)}{d \omega_{3}(t)}, \\
& \left(\gamma_{3}-\gamma_{1}\right) \mathrm{E} W_{1}+\left[\left(N_{1}-n\right) \gamma_{1}+n \gamma_{3}\right] \frac{d \mathrm{E} W_{1}}{d n}+N_{2} \gamma_{2} \frac{d \mathrm{E} W_{2}}{d n} \\
& +\sum_{t} \alpha(t)\left[\omega_{1}(s, t)-\omega_{3}(t)+\frac{d \Omega(t)}{d n}\right]-\mu\left(\frac{d \mathrm{E} W_{1}}{d n}-\frac{d \mathrm{E} W_{3}}{d n}\right)=0
\end{aligned}
$$

for all $s, t$. Equation (11) implies that the allocation of wealth among individuals should equalize the weighted ex ante utility across all individual types in a given collective state $t$. In this sense, rural workers' consumptions are not dependent on individual states any more, $\omega_{1}(s, t)=\omega_{1}(t)$ for all $s, t$. Equation (12) implies that the allocation of labor (the number of seasonal workers) must equalize marginal social benefit and marginal social cost of having one more rural resident to work in the urban sector. 
If we assume ex ante utility function is in log form (the degree of relative risk aversion is 1), the optimization problem can be solved as $\omega_{i}(t)=\rho_{i} \Omega(t)$, with:

$$
\begin{aligned}
& \rho_{2}=\frac{\gamma_{2}}{\gamma_{1}\left(N_{1}-n\right)+\gamma_{2} N_{2}+\gamma_{3} n} \\
& \rho_{1}=\frac{\mathrm{e}^{A_{3}}}{\left[\left(N_{1}-n\right) \mathrm{e}^{A_{3}}+n \mathrm{e}^{A_{1}}\right]}\left(1-N_{2} \rho_{2}\right), \text { for all } t \\
& \rho_{3}=\frac{\mathrm{e}^{A_{1}}}{\left[\left(N_{1}-n\right) \mathrm{e}^{A_{3}}+n \mathrm{e}^{A_{1}}\right]}\left(1-N_{2} \rho_{2}\right)
\end{aligned}
$$

in which $\mathrm{e}^{\alpha}$ denotes the Natural logarithm with $\alpha_{i}=\sum_{t} \pi(t) \ln A_{i}(t)$.Equation (13) implies that individuals of the same type can consume the amount of goods worth a fixed proportion of social aggregate economic value, independent of the state of the world.

\section{INSURANCE MARKET ALLOCATION OF DISASTER RISK}

When there is M.A. insurance system in this small world, the sequence of events change to: a) decision-making on migration; b) underwriting of M.A. insurance policy; c) production; d) determination of the state of the world; e) exercise of insurance contract, trade, and consumption. For the convenience of discussion, we still allow individuals to pay premium of M.A. insurance ex post. The individuals' optimization problem is denoted by the equation below:

$$
\max _{m(s, t), a_{i}(t)} \mathrm{E} W_{i}=\sum \pi(\cdot) W_{i}\left(v_{i}\left(\omega_{i}(\cdot)\right)\right), \text { for } i=1,2,3
$$

subject to

$$
\begin{aligned}
\omega_{1}(s, t) & =e_{1}(s, t)+\left[m(s, t)-\sum_{s^{\prime}} \pi\left(s^{\prime} \mid t\right) m\left(s^{\prime}, t\right)\right] \\
& +\left[a_{i}(t)-\sum_{t^{\prime}} r\left(t^{\prime}\right) a_{i}\left(t^{\prime}\right)\right] \\
\omega_{i}(t) & =e_{i}(t)+\left[a_{i}(t)-\sum_{t^{\prime}} r\left(t^{\prime}\right) a_{i}\left(t^{\prime}\right)\right], i=2,3 \\
e_{1}(s, t) & =p(t) X(s), e_{2}(t)=w(t), e_{3}(t)=w(t)-c
\end{aligned}
$$

for all $s, t . m(s, t)$ is the mutual insurance coverage against a joint state of $(s, t)$. Urban workers do not use the mutual insurance system as they have no difference in their individual states. $a_{i}(t)$ denotes the amount of Arrow security held by individual of type $i$ and $r(t)$ denoting the market-clearing price of per unit of Arrow security against a collective state $t$.

The M.A. insurance market equilibrium implies that fullcover mutual insurance

$$
m_{1}(s, t)=p(t)[X(0)-X(s)], \text { for all } s, t,
$$

where we use $X(0)$ to denote the individual damage-free state. In this sense, after fulfilling the mutual insurance contract, rural workers have the same state-contingent wealth equal to the expected labor income across all individual states. Finally, the equilibrium of M.A. insurance system follows

$$
\begin{gathered}
r(t)=\frac{\pi(t)}{\Omega(t)} / \sum_{t^{\prime}} \frac{\pi\left(t^{\prime}\right)}{\Omega\left(t^{\prime}\right)}, \text { for all } t \\
\lambda_{i}=\sum_{t} \frac{\pi(t)}{\Omega(t)} / \sum_{t} \pi(t) \frac{e_{i}(t)}{\Omega(t)}, \\
\omega_{i}(t)=\Omega(t) \sum_{t^{\prime}} \pi\left(t^{\prime}\right) e_{i}\left(t^{\prime}\right) / \Omega\left(t^{\prime}\right), \text { for all } t
\end{gathered}
$$

It is an interesting feature of the M.A. insurance to allow individuals of the same type to consume exactly the amount of goods with a fixed proportion of social aggregate economic value irrespective of the state the world.

\section{EFFICIENCY ISSUES}

We are interested in how factor mobility and goods tradability affect the efficiency of allocating resources as well as disaster risk in this small world. In order to make the social optimum and market solution comparable, we apply the necessary condition for equivalency of social optimum and market solution [13], $\gamma_{i} \lambda_{i}=1$. As equations are not tractable analytically, numerical examples are employed to show the impact intuitively. For instance, let

$t=(0,1), \pi(t=0)=0.5 \pi(t=1)=0.5 ; s=(0,1), \pi(0 \mid 0)=1$, $\pi(1 \mid 0)=0, \quad \pi(0 \mid 1)=1 / 3, \quad \pi(1 \mid 1)=2 / 3 ; \quad N_{1}=30000$, $N_{2}=10000 ; \quad X(0)=20, \quad X(1)=5 ; \quad w(0)=30, \quad w(1)=20$; $\operatorname{EX}(0)=20, \operatorname{EX}(1)=10 ; \epsilon=1 ;$ and use $\delta_{x}=\delta_{y}=\delta$ and $c$ as parameters. Numerical results are shown in Fig. 2 and Fig. 3.

The numerical examples imply that when goods tradability is perfect, M.A. insurance market can achieve social optima. If there is no insurance market working, the seasonal move should be discouraged. When goods tradability is not perfect with positive transaction costs, the social optima and M.A. insurance equilibria diverge. Seasonal moves should be encouraged when the transaction costs for shipping goods are high, or vice versa.

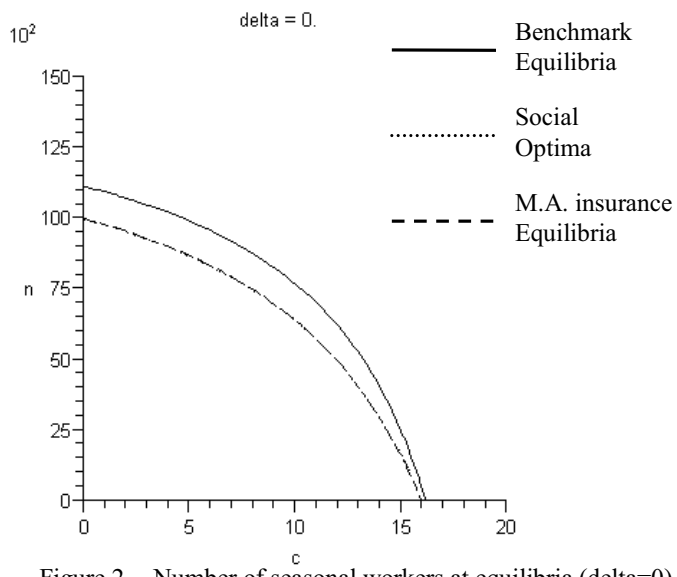

Figure 2. Number of seasonal workers at equilibria (delta $=0$ ) 


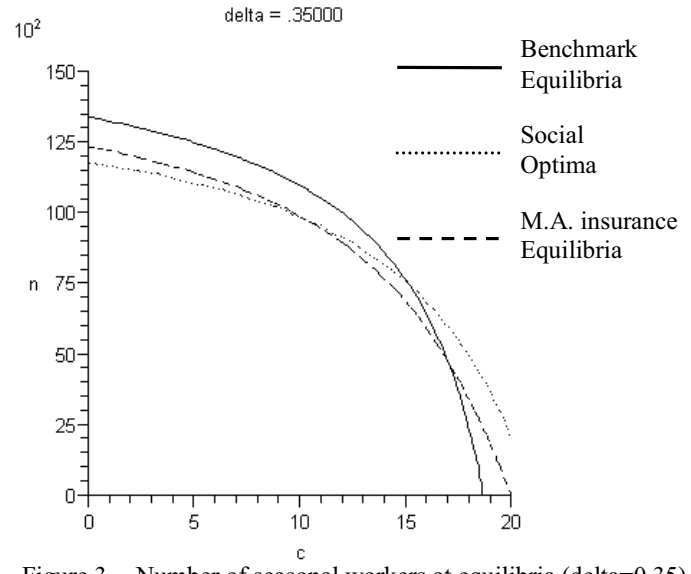

Figure 3. Number of seasonal workers at equilibria (delta $=0.35)$

The divergence implies that externality is induced due to the existence of imperfect goods tradability, the transaction costs in transporting goods between rural and urban areas in this model. Therefore, government intervention is necessary to modify the M.A. insurance equilibrium.

\section{GOVERNMENT INTERVENTION}

In order to save the efficiency loss induced by the externality, the intervention is expected to change rural residents' decision-making about seasonal move. There are two types of government intervention to achieve the desirable efficient allocation of labor force between sectors.

\section{1) Lump-sum transfer}

Suppose that the government uses lump-sum transfer of wealth in terms of urban goods among three types of individuals, budget constraints of individuals change to:

$$
\begin{aligned}
\omega_{i}(t) & =e_{i}(t)+\left[a_{i}(t)-\sum_{t^{\prime}} r\left(t^{\prime}\right) a_{i}\left(t^{\prime}\right)\right]+\tau_{i} \\
e_{1}(t) & =p(t) \operatorname{EX}(t), e_{2}(t)=w(t), e_{3}(t)=w(t)-c
\end{aligned}
$$

and $i=1,2,3$. In (19) $\tau_{i}$ is the lump-sum transfer of wealth which is assumed to be conducted ex ante. In this sense it represents tax/ subsidy against the seasonal move when it is negative/ positive. The sequence of events changes to: firstly the government announces the lump-sum transfer program; rural residents adjust decision-making on the seasonal move taking government policy into account; by observing rural residents' behavior, the government chooses its optimal intervention strategy to adjust the number of seasonal worker to the social optimal one.

The individual's optimization problem implies that:

$$
\omega_{i}(t)=\Omega(t) \sum_{i} \pi\left(t^{\prime}\right)\left[e_{i}\left(t^{\prime}\right)+\tau_{i}\right] / \Omega\left(t^{\prime}\right)=\Omega(t) \rho_{i}^{L},
$$

which is straightforward by substituting $e_{i}(t)+\tau_{i}$ for $e_{i}(t)$ in (18). Again we observed that individuals' state-contingent wealth is a fixed proportion of social aggregate wealth even with government intervention, denoted by $\rho_{i}^{L}$. Then the redistributive vector achieves efficiency if the number of seasonal workers determined by the market approach with government intervention equals the social optimal one. If $\rho_{i}^{L^{*}}$ meets the requirement, the intervention plan can be denoted as:

$$
\tau_{i}=\left[\rho_{i}^{L^{*}}-\sum_{t} \frac{\pi(t) e_{i}(t)}{\Omega(t)}\right] / \sum_{t} \frac{\pi(t)}{\Omega(t)}
$$

Note that we can have a number of intervention strategies that guarantees $\mathrm{E} W_{1}$ and $\mathrm{E} W_{3}$ equalized at the social optimal population distribution pattern. The government can do so by allocating rural and seasonal workers a lot of goods but urban residents only a few to consume, or vice versa. This situation occurs because urban residents have nothing to do with the allocation of labor and the government can allocate them any arbitrary amount of goods without losing efficiency. If the central planner wishes to maximize social welfare simultaneously then the intervention should let $\rho_{2}^{L^{*}}=\rho_{2}$ as determined in (13). Alternatively, if the government wants to make the working-load and side effect of intervention minimum, then just simply let $\tau_{2}=0$.

It is straightforward that the budget constraint of the government holds, $\left(N_{1}-n\right) \tau_{1}+N_{2} \tau_{2}+n \tau_{3}=0$, as budget constraints of all other groups of individuals hold.

2) Subsidy system on insurance premium.

The intervention strategy is as follows: the government imposes a tax $\chi_{i}$ on individual of type $I$ and offer mandatory premium rates $R_{i}(t)$ for them. Individuals choose personal optimum amount of insurance coverage, $a_{i}(t)$, taking $\chi_{i}$ and $R_{i}(t)$ as exogenous parameter. After observing individuals' optimum behavior, the government chooses combinations of $\chi_{i}$ and $R_{i}(t)$ to adjust the number of seasonal workers to the social optimal one; then the subsidy system with subsidy on premium rate $R_{i}(t)-r_{i}(t)$ and lump-sum tax $\chi_{i}$ is determined.

Therefore firstly let us look at the optimization problem of individuals. The budget constraints are:

$$
\begin{aligned}
& \zeta_{i}(t): \omega_{i}(t)=e_{i}(t)-\chi_{i}+\left[a_{i}(t)-\sum_{t^{\prime}} R_{i}\left(t^{\prime}\right) a_{i}\left(t^{\prime}\right)\right] \\
& e_{1}(t)=p(t) \operatorname{EX}(t), e_{2}(t)=w(t), e_{3}(t)=w(t)-c
\end{aligned}
$$

First-order conditions can be derived as:

$$
\begin{aligned}
\pi(t) / \omega_{i}(t)-\zeta_{i}(t) & =0 \\
\zeta_{i}(t)-R_{i}(t) \sum_{t^{\prime}} \zeta_{i}\left(t^{\prime}\right) & =0
\end{aligned}
$$

and optimal choices can be derived as:

$$
\omega_{i}(t)=\pi(t) \sum_{t^{\prime}} R_{i}\left(t^{\prime}\right)\left[e_{i}\left(t^{\prime}\right)-\chi_{i}\right] / R_{i}(t)
$$

The subsidy system on insurance premium is successful if the number of seasonal workers determined by this intervened market equilibrium equals the social optimal one. If the redistribution $\omega_{i}^{P^{*}}(t)$ satisfies this point, the intervention strategy is determined by:

$$
R_{i}(t)=\frac{\pi(t)}{\omega_{i}^{P^{*}}(t)} / \sum_{t^{\prime}} \frac{\pi\left(t^{\prime}\right)}{\omega_{i}^{P *}\left(t^{\prime}\right)}, \chi_{i}=\left[\sum_{t} \frac{\pi(t) e_{i}(t)}{\omega_{i}^{P *}(t)}-1\right] / \sum_{t} \frac{\pi(t)}{\omega_{i}^{P *}(t)},
$$


for all $t$. Again there are a number of intervention strategies for the same reason as mentioned before. The budget constraint of the government is automatically met since all other groups of agents are following their budget constraints.

\section{CONCLUSION AND DISCUSSION}

The authors have constructed a model to discuss the disaster risk diversification and labor allocation problem between rural and urban sectors. It takes a focus on the migration behavior (the seasonal move in this model) as a sort of risk management practice of rural labors. The result of the model implies that it is inappropriate to argue whether the government should encourage or discourage rural residents to move to work in urban sectors universally. It can be seen in the model that when goods are assumed to be free to trade, the number of seasonal workers should always be controlled, either with centralized or decentralized instruments. When the transaction costs for shipping goods are taken into account, however, rural residents should be discouraged to work in the urban sector to some extent in case that the transaction costs for moving is low, or vice versa. When goods are perfectly tradable, the M.A. insurance market allocates exactly social optimal number of seasonal workers. When goods tradability is not perfect, however, externality rises and the M.A. insurance system cannot achieve efficient allocation of labor between sectors.

Government intervention is necessary to correct the efficiency loss induced by the externality. The paper proposed two types of intervention strategy. The one is lump-sum tax/subsidy on the seasonal move and the other is subsidy system on insurance premium which is widely adopted in many countries. The proportional instrument, however, needs large amount of private information of individuals since it is implemented based on individual-dependent lump-sum tax and proportional subsidies. Although the impact cannot be revealed in the structure of this model, its operation in reality must be very difficult and of high transaction costs.

The authors believe that what is happening in most less developed countries follows the benchmark case with imperfect goods tradability and a few government redistributive policies. In this sense, the number of seasonal workers is likely to lie between the one in the benchmark equilibrium and social optimum one. Private insurance market, even it is perfect firstbest insurance market, cannot substitute for government redistributive policy and intervention is necessary. Specific policies depend on specific economic environment. Particularly, the criteria for "high" or "low" or the transaction costs is vague in the current model, which requires further empirical works to reveal.

There are still several important issues that have not well framed and explained in this model. The CES utility function cannot reflect some important features of agriculture goods, especially subsistence products. A group of utility functions showing inelastic demand with respect to rural goods and perhaps embodying subsistence constraint of consumption will help to track the essential issues of disaster risk management for agriculture production better. Secondly, although the subsidy system on insurance premium is justified, it will be more appreciated if premium subsidy is framed as Pigovian tax/subsidy which equalizes the marginal social and individual costs in insuring disaster risk. In that case, the externality must be induced in the insuring process, which is beyond the structure of the current model.

\section{ACKNOWLEDGMENT}

This research has been financially supported by National Natural Science Foundation of China Key Project (NSFC No. 40535024) and DRH (Disaster Reduction Hyper-base) CASiFiCA (Case Station -- Field Campus) project funded by Special Coordination Fund for Promoting Science and Technology, Ministry of Education, Culture, Sports, Science and Technology of Japan. The authors are grateful to researchers involved in the discussion of this paper and anonymous referees who gave invaluable comments and suggestions.

\section{REFERENCE}

[1] B. F. Johnston and J. W. Mellor, "The role of agriculture in economic development”, Amer. Econ. Rev. , Vol. 51, pp. 566-593, 1961.

[2] D. G.Johnson, "Role of agriculture in economic development revisited", Agricultural Economics, Vol. 8, pp. 421-434, 1993.

[3] C. P. Timmer, "Agriculture and economic development revisited", Agriculture Systems, Vol. 40, pp. 21-58, 1992

[4] R. K. Goodwin and V. H. Smith, The Economics of Crop Insurance and Disaster Aid. Washington, D. C: The AEI Press, 1995.

[5] A. K. Dixit and J. B. Londregan, "Redistributive politics and economic efficiency", American Political Science Review, Vol. 89, pp. 856-866, 1995.

[6] J. Ito, "The removal of institutional impediments to migration and its impact on employment, production and income distribution in China", Econ Change Restruct, Vol. 41, pp. 239-265, 2008. doi: 10.1007/ s10644-008-9051-7.

[7] The State Council of China, "Some opinions of the state council on the reform and development of the insurance industry", http://www. xinhuanet.com, 2006. (accessed on Nov 17, 2007)

[8] W. Oates, Urban Public Finance. Harcourt Brace Jovanovich, 1972.

[9] D. E. Wildasin, Urban Public Finance. Chur, London, Paris, New York: Harwood Academic Publishers, 1986.

[10] E. Malinvaud, "The allocation of individual risks in large markets," Journal of Economic Theory, Vol. 4, pp. 312-328, 1972.

[11] E. Malinvaud, "Markets for an exchange economy with individual risks," Econometrica, Vol. 41, pp. 383-410, 1973.

[12] D. Cass, G. Chichilnisky, and H. M. Wu, "Individual risk and mutual insurance," Econometrica, Vol. 64, No. 2, pp. 333-341, 1996.

[13] M. Yokomatsu and K. Kobayashi, "Catastrophic risks and economic valuation of disaster mitigation," Paper presented on the Second Euro Conference on Global Change and Catastrophe Risk Management: Earthquake Risks in Europe, July 6-9, 2000, IIASA, Austria.

[14] T. Ye, M. Yokomatsu and N. Okada, "Inter-sectoral allocation of risk: is inter-sectoral fiscal transfer creating the right incentives?", No. 52 of Annuals of Disaster Prevention Research Insitute, Kyoto University, 2009. (forthcoming)

[15] Y. Zhao, "Leaving the countryside: rural-to-urban migration decisions in China", AEA Papers and Proceedings, Vol. 89, No. 2, pp. 281-286, 1999a.

[16] Y. Zhao, "Labor migration and earnings differences: the case of Rural China", Economic Development and Cultural Change, Vol. 47, No. 4, pp 767-782, $1999 \mathrm{~b}$. 